\title{
Sub-typing of renal cell tumours; contribution of ancillary techniques
}

\author{
Dinesh Pradhan $^{\dagger 1}$, Nandita Kakkar ${ }^{\dagger 1}$, Amanjit Bal ${ }^{\dagger 1}$, Shrawan Kumar Singh ${ }^{\dagger 2}$ \\ and Kusum Joshi*1
}

Address: ${ }^{1}$ Department of Histopathology, Post Graduate Institute of Medical Sciences \& Research, (PGIMER), Chandigarh, India and ${ }^{2}$ Advanced Urology Centre, Post Graduate Institute of Medical Sciences \& Research, (PGIMER), Chandigarh, India

Email: Dinesh Pradhan - dppgi4u@gmail.com; Nandita Kakkar - nandita_kakkar@yahoo.com; Amanjit Bal - docaman5@hotmail.com; Shrawan Kumar Singh - pgimer@chd.nic.in; Kusum Joshi* - kus_joshi@yahoo.com

* Corresponding author †Equal contributors

Published: 28 June 2009

Diagnostic Pathology 2009, 4:21 doi:10.1186/1746-1596-4-21
Received: 12 May 2009

Accepted: 28 June 2009

This article is available from: http://www.diagnosticpathology.org/content/4/I/2I

(c) 2009 Pradhan et al; licensee BioMed Central Ltd.

This is an Open Access article distributed under the terms of the Creative Commons Attribution License (http://creativecommons.org/licenses/by/2.0), which permits unrestricted use, distribution, and reproduction in any medium, provided the original work is properly cited.

\begin{abstract}
Background: Adult renal epithelial neoplasms are a heterogeneous group with varying prognosis and outcome requiring sub-classification.

Methods: Cases of renal cell carcinoma (RCC) in a 10 years period were analyzed with regard to the clinical features and histology. Sections were reviewed by four pathologists and the discordant cases were resolved with the help of Hale's colloidal iron stain, vimentin, CK 7, and vinculin immunostains and electron microscopy.
\end{abstract}

Results: Amongst the total of 278 cases, clear cell renal cell carcinoma was the commonest tumor with $74.8 \%$ cases, followed by papillary RCC $12.2 \%$, chromophobe RCC $7.9 \%$, oncocytoma $1.8 \%$, and one case of collecting duct RCC. Eight cases were of sarcomatoid renal cell carcinoma. In 28/ 278 cases, diagnoses varied amongst the four pathologists and the discordance was resolved by Hale's colloidal iron stain, CK7 immunostain and electron microscopy. Vimentin and vinculin did not contribute much in differentiating subtypes of renal cell carcinomas. Relative incidence of subtypes of RCCs was compared with other series

Conclusion: To accurately subclassify renal cell carcinomas, simple ancillary techniques would possibly resolve all difficult cases. The relative incidence of sub-types of renal cell carcinoma is relatively consistent the world over. However, in India, RCCs afflict the patients two decades earlier.

\section{Background}

Renal cell carcinoma (RCC), accounts for $2-3 \%$ of all new cancers diagnosed and $85 \%$ of all primary renal neoplasms in adults[1]. Adult renal epithelial neoplasms are a heterogeneous group comprised of subtypes that have distinct gross, histologic, ultrastructural, and immunohistochemical features. These morphologic distinctions are amply supported by unique cytogenetic and chromosomal aberrations for many of the subtypes $[2,3]$. Thus classification of renal cell carcinoma is important from the treatment and prognosis point of view as well as for understanding its histogenesis, molecular and cytogenetic behaviour for further improvement in its management approach. 
Keeping this in view, many classification systems have been made till date. Mainz classification[4] and subsequently AFIP classification[5] sub-classified these tumours purely based on morphological grounds. However, the first classification based on molecular and cytogenetic studies and on the cell of origin of each entity came into being in 1997 as the Heidelberg classification[6]. Subsequently, WHO classified renal cell tumors into clear cell RCC, multilocular clear cell RCC, papillary RCC, chromophobe RCC, carcinoma of the collecting ducts of Bellini, renal medullary carcinoma, Xp11 translocation carcinoma, carcinoma associated with neuroblastoma, mucinous tubular and spindle cell carcinoma, renal cell carcinoma-unclassified, papillary adenoma and oncocytoma[7].

Whilst a majority of renal cell carcinomas seen in routine practice of surgical pathology, are easy to diagnose based on haematoxylin and eosin preparation alone, there is insufficient information on how to deal with the differential diagnoses regarding subtypes of RCC. The present study aims at classifying adult renal tumors based on the cell of origin, by histomorphology, immunohistochemistry, and ultrastructural studies.

\section{Methods}

The material of this study was derived from cases of renal cell carcinoma received in the Department of Histopathology, Post Graduate Institute of Medical Education and Research PGIMER, Chandigarh from July, 1997 to June, 2007 (ten years period).

Patients aged more than 16 years were included in the study. All the cases were routinely fixed in $10 \%$ buffered formalin. $4 \mu$ sections were cut and haematoxylin and eosin staining was performed in routine using the standardized methods. Haematoxylin and eosin stained sections were reviewed by independent pathologists in a blinded manner and the diagnosis of the four pathologists were compared. All cases with discordant diagnosis or in which a definitive diagnosis on the basis of morphology was not possible were taken up for further study which included histochemical, immunohistochemical, and ultrastructural analysis.

\section{Hale's colloidal iron stain}

Cases in which chromophobe cell carcinoma was kept as possibility by any of the three observers were taken up for Hale's colloidal iron stain. The method of Hale's colloidal iron stain used was a modification published by Tickoo et al[8].

\section{Immunohistochemistry}

All the cases with discordant diagnoses were taken up for immunohistochemistry; vimentin (Dako Cytomation,
1:50 dilution), Cytokeratin 7(Dako Cytomation, 1:50 dilution), and vinculin (Santa Cruz Biotechnology, 1:40 dilution) according to the differential diagnosis kept in a given case and with a minimum of 5 cases in each subgroup and including all 5 oncocytomas.

Immunostaining was carried out on $4 \mu$ paraffin sections after antigen retrieval using pressure cooker method. The sections were incubated with appropriately diluted primary antibody, washed in PBS $(3 \times 5 \mathrm{~min})$ and then incubated with peroxidase conjugated secondary antibody. Color reaction was developed by DAB and counterstained by hematoxylin. Appropriate positive and negative controls were taken. Immunoreactivity was evaluated by taking into account the percentage positivity of tumor cells. Positivity was taken as a brown reaction product staining the cytoplasm. The cells were scored as negative or positive and the percentage of positive tumor cells were recorded, which ranged from $0-100 \%$. The percentage positivity was graded from $1+$ to $3+$ as follows:-

$$
\begin{aligned}
& 5-25 \% \quad--1+ \\
& 25-75 \% \quad--2+ \\
& >75 \% \quad--3+
\end{aligned}
$$

\section{Electron Microscopy}

Ultrastructural analysis of selected cases was done to confirm the diagnosis, when required. The tissue for electron microscopy was taken from formalin fixed tissue of all cases of oncocytoma and representative cases from discordant groups. Tissue blocks were fixed in 3\% buffered glutaraldehyde and processed for electron microscopy by routine methods. The grids were examined under Zeiss 906 electron microscope, and representative photographs were taken under suitable magnification.

\section{Results}

A total of 278 cases of renal cell carcinoma were included in this study. Age of the patients ranged from 16-78 years, the average being 52 years ( mean $=51.45$ ). The peak incidence was in the fourth and fifth decades and the male to female ratio of 2.3:1. Out of these 278 renal carcinomas, concordant diagnoses were obtained in 250 cases whereas in the remaining 28 cases, diagnosis varied amongst the four pathologists. The discordance was resolved by histochemistry, immunohistochemistry and electron microscopy as detailed in Table 1. Table 2 shows incidence of sub-types of RCCs amongst the total of 278 cases.

Clear Cell RCC was the most common kidney tumor accounting for $74.8 \%$ (208/278) of all adult renal tumors. They exhibited a male preponderance and mean age at presentation of 56.2 years. Clear cell RCC were mostly sol- 
Table I: Detailed Description of Discordant Cases $(\mathbf{N}=\mathbf{2 8})$

\begin{tabular}{|c|c|c|c|c|c|c|c|}
\hline S. No. & Diagnosis & Hale's stain & Vimentin & CK 7 & Vinculin & EM & Final Diagnosis \\
\hline I & CCRCC vs papillary & & - & - & - & & Papillary RCC \\
\hline 2 & CCRCC vs Chromophobe & - & + & - & - & & Conventional RCC \\
\hline 3 & Papillary RCC vs CCRCC & & - & - & - & & Conventional RCC \\
\hline 4 & Chromophobe RCC vs CCRCC & + & + & $3+, m$ & - & PNV & Chromophobe RCC \\
\hline 5 & Papillary RCC vs CCRCC & & $3+$ & + & - & & Papillary RCC \\
\hline 6 & Collecting duct RCC vs Papillary & & $2+$ & $3+$ & - & & Papillary RCC \\
\hline 7 & CCRCC vs papillary & & + & $2+$ & - & & Papillary RCC \\
\hline 8 & $A C C$ vs CCRCC & & $3+$ & - & - & & Conventional RCC \\
\hline 9 & Chromophobe RCC vs CRCC & + & - & $2+, m$ & - & & Chromophobe RCC \\
\hline 10 & CCRCC vs Papillary & & + & - & - & & Conventional RCC \\
\hline II & Collecting duct RCC vs CCRCC & & $2+$ & $2+$ & $2+$ & & Collecting duct RCC \\
\hline 12 & CCRCC vs oncocytoma & & - & - & - & & Conventional RCC \\
\hline 13 & Chromophobe vs CCRCC & - & + & - & - & & Conventional RCC \\
\hline 14 & Chromophobe vs CCRCC & + & - & $2+, \mathrm{m}$ & - & PNV & Chromophobe RCC \\
\hline 15 & Chromophobe vs CCRCC & - & - & - & - & & Conventional RCC \\
\hline 16 & CCRCC vs papillary & & - & + & - & & Papillary RCC \\
\hline 17 & CCRCC vs Sarcomatoid & & - & - & - & & Sarcomatoid RCC \\
\hline 18 & Papillary RCC vs CCRCC & & + & $2+$ & - & & Papillary RCC \\
\hline 19 & Chromophobe vs CCRCC & + & - & $2+, m$ & - & & Chromophobe RCC \\
\hline 20 & Chromophobe RCC vs CCRCC & - & - & - & - & Glycogen & Conventional RCC \\
\hline 21 & Chromophobe vs CCRCC & - & $2+$ & - & - & & Conventional RCC \\
\hline 22 & CCRCC vs chromophobe & - & $3+$ & $3+$ & - & & Papillary RCC \\
\hline 23 & Chromophobe vs oncocytoma & & - & $3+$ & - & PNV & Chromophobe RCC \\
\hline 24 & CC RCC vs papillary & & $2+$ & $3+$ & - & No PNV & Papillary RCC \\
\hline 25 & Chromophobe vs CCRCC & + & $2+$ & + & - & & Chromophobe RCC \\
\hline 26 & CCRCC vs Chromophobe & + & - & $3+, m$ & - & & Chromophobe RCC \\
\hline 27 & CCRCC vs papillary & & - & - & - & & Conventional RCC \\
\hline 28 & Oncocytoma vs ACC vs CCRCC & & - & - & - & & Conventional RCC \\
\hline
\end{tabular}

CCRCC - Conventinal/clear cell RCC, ACC - adrenocortical carcinoma, m - membranous accentuation, PNV-Perinuclear vesicles

itary and bilaterality was noted in a single case. Fuhrman grading revealed that $85 \%$ of clear cell renal cell carcinomas were grade 1 and 2, and less than $5 \%$ were grade 4 . Multicystic clear cell renal cell carcinoma was noted in 5 cases, 4 of which were nuclear grade 1 and one case was nuclear grade 2. Cytoplasmic inclusions were noted in 78 cases. Well formed psammoma bodies and fibro-calcific bodies were seen in 2 cases each; however calcification, cholesterol clefts, hemosiderin pigment and hyaline globules were seen in many cases. Areas with rhabdoid differentiation were noted in 2 cases while granulomatous inflammation was noted in the adjoining lymph node in another 2 cases. Sarcomatoid change was seen in 5 cases. One case revealed membranous glomerulonephritis in the adjoining renal parenchyma. Invasion of peri-renal fat and extension into the renal vein with thrombosis was noted in two cases.

Papillary (or chromophilic) renal cell carcinomas comprised $12.2 \%(n=34)$ of cases. The mean age at presentation was 52.4 years and the sex ratio was $\mathrm{M}: \mathrm{F}=2.1: 1$. Based upon morphology two types of PRCC were categorized; Type 1 tumours (27/34 cases) had papillae covered by small cells with scanty basophilic cytoplasm, arranged

Table 2: Sub-types of Renal Cell Carcinomas amongst total cases $(\mathbf{N}=\mathbf{2 7 8})$

\begin{tabular}{|c|c|c|}
\hline SUBTYPES OF RCC & $\begin{array}{c}\text { INCIDENCE (\%) } \\
\text { Concordant cases } \\
(n=250)\end{array}$ & $\begin{array}{c}\text { INCIDENCE (\%) } \\
\text { Total Cases } \\
(n=278)\end{array}$ \\
\hline Conventional or clear cell RCC (CCRCC) & 197(78.8) & 208(74.8) \\
\hline Papillary RCC (PRCC) & $26(10.4)$ & $34(12.2)$ \\
\hline Chromophobe RCC (CRCC) & $15(6)$ & $22(7.9)$ \\
\hline Renal oncocytoma (RO) & $5(2)$ & $5(1.8)$ \\
\hline Collecting duct RCC (CDRCC) & $0(0)$ & $\mathrm{I}(0.4)$ \\
\hline Sarcomatoid RCC (SRCC) & $7(2.8)$ & $8(2.9)$ \\
\hline
\end{tabular}


in a single layer on the papillary basement membrane and Type 2 tumours (7/34 cases) had cells of higher nuclear grade with eosinophillic cytoplasm and pseudostratified nuclei on papillary cores. Out of the 34 cases of papillary RCC, 6 (17.6\%) cases were Fuhrman's nuclear grade 1, 15 $(44.1 \%)$ cases were grade $2,11(32.4 \%)$ cases were grade 3 and 2

(5.9\%) cases were grade 4 . Sarcomatoid dedifferentiation was seen in only 1 case. Four cases showed psammoma bodies and 1 case showed fibro-siderotic nodules. Invasion of peri-renal fat and extension into the renal vein with thrombosis was noted in one case of PRCC. Another 1 case of PRCC showed lymph node metastasis.

Chromophobe renal cell carcinomas comprised 7.9\% ( $\mathrm{n}=$ 22) of all renal cell carcinomas. The mean age at presentation was 46.8 years and there was a slight female preponderance. The eosinophilic variant of chromophobe carcinoma was found in 7 cases and was purely composed of intensely eosinophilic cells with prominent cell membranes. Four cases (18.2\%) were Fuhrman's nuclear grade $1,11(50 \%)$ cases were grade 2, $6(27.3 \%)$ cases were grade 3 and 1 (4.5\%) case was grade 4 . Well formed psammoma bodies were seen in 2 cases, however, calcification, cholesterol clefts, hemosiderin pigment and hyaline globules were seen in many cases. Sarcomatoid transformation was noted in 2 cases.

Renal oncocytoma comprised 1.8\% ( $\mathrm{n}=5)$ of all renal cell carcinomas. The mean age at presentation was 48 years with a slight female preponderance. The cells were roundto polygonal with densely granular eosinophilic cytoplasm.

\section{Others}

Only one case of collecting duct carcinoma in a 70 year male was seen. The cells of collecting duct carcinoma displayed high nuclear grade (Fuhrman 4). Sarcomatoid RCC was noted in $2.9 \%(\mathrm{n}=8)$ of all adult renal cell carcinomas. The mean age at presentation was 66.2 years with a male preponderance. As the sarcomatoid element overshadowed the original antecedent carcinoma to the extent that it could not be recognized, so it was kept under Sarcomatoid RCC or unclassified category (according to the recent $\mathrm{WHO}$ ).

\section{Discordant cases (Table I)}

Most (12/28 cases) of the discordance was between clear cell RCC and chromophobe RCC. This was solved by Hale's colloidal iron stain which yielded a diffuse blue granular cytoplasmic staining in chromophobe renal cell carcinoma(Fig. 1) and pink periodic acid Schiff positivity in cytoplasm of clear cell renal cell carcinoma cells. Other subtypes of RCC were negative. This stain was very helpful

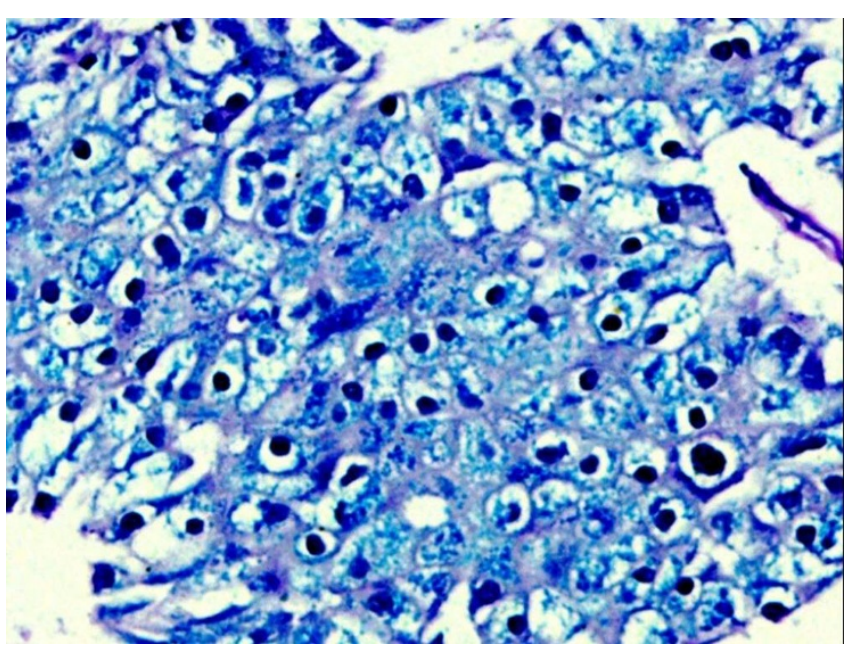

Figure I

Photomicrograph of Hale's colloidal iron stain showing deep blue granular cytoplasmic positivity in chromophobe RCC ( $\mathrm{HCl}$ with hematoxylin counterstain, $\times 200$ ).

and statistically significant $(\mathrm{p}<0.0001)$ in differentiating chromophobe renal cell carcinoma from other subtypes of RCC. CK7 was also positive in all cases of chromophobe RCC and negative in clear cell RCC. Next group of discordance was between clear cell RCC, with papillary areas and papillary RCC (10/28) which was resolved by CK7 immunostain which was positive in most of the cases $(90 \%)$ of papillary RCC and was negative in all cases of clear cell RCC. Third group of discordance was between eosinophilic variant of chromophobe RCC and oncocytoma. This discordance was resolved by CK7 immunostain which was positive in all cases of chromophobe RCC and was negative in oncocytoma. Electron microscopy was of diagnostic importance in oncocytomas by showing cytoplasm packed with mitochondria to the exclusion of other organelles.

\section{Immunohistochemistry}

Vimentin was positive in $53.9 \%(7 / 13)$ cases of clear cell renal cell carcinoma and $80 \%(8 / 10)$ cases of papillary renal cell carcinoma. It was positive in $2(20 \%)$ cases of chromophobe RCC. One case of collecting duct RCC showed focal positivity in stromal cells. Oncocytomas showed negative vimentin staining $(0 / 5)$.

CK 7 (Fig. 2 and 3): was positive in $90 \%(9 / 10)$ cases of papillary renal cell carcinoma $(\mathrm{p}<0.001)$ and was more frequently observed in type $1(100 \%)$ than type $2(75 \%)$ tumours. All the cases of chromophobe renal cell carcinoma (10/10) and collecting duct carcinoma (1/1) were positive. It was negative in all 20 cases of clear cell renal cell carcinoma and 5 cases of renal oncocytoma. 


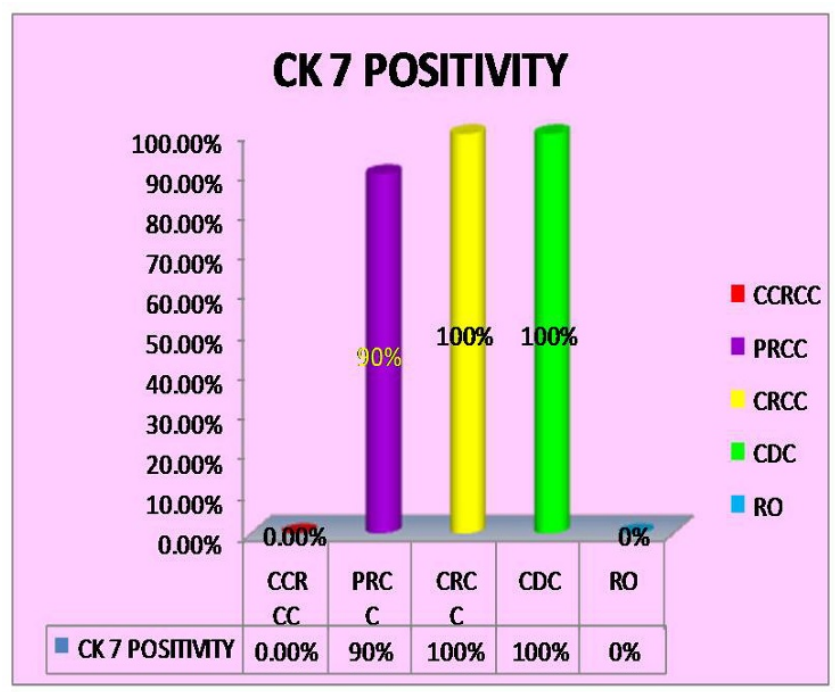

Figure 2

Bar diagram showing CK7 positivity in RCC(CCRCCClear cell renal cell carcinoma; PRCC-Papillary renal cell carcinoma; CRCC-Chromophobe renal cell carcinoma; CDC-Collecting duct carcinoma; RO-Renal Oncocytoma).

Vinculin (Fig. 4) was weakly but distinctly positive on the cell membrane of only 2/15 cases of chromophobe RCC and 1 case of collecting duct RCC. It was negative in all cases of clear cell renal cell carcinoma (0/13), papillary renal cell carcinoma $(0 / 12)$ and renal oncocytoma $(0 / 5)$. It was not found to be useful in resolving the differential diagnosis because of its low sensitivity in cases of chromophobe RCC.

\section{Electron Microscopy}

Ultrastructural examination was done in renal oncocytoma(5 cases), chromophobe renal cell carcinoma (7 cases), and 2 cases each of eosinophilic variants of clear cell renal cell carcinoma and type 2 papillary RCC. Special attention was paid to mitochondria and microvesicles and interrelations thereof. The cytoplasm of all the oncocytomas were packed with abundant mitochondria (Fig. 5). Although abundant microvesicles were present in all the chromophobe renal cell carcinomas, but scant numbers of microvesicles were also present in renal oncocytomas and in the eosinophilic variant of clear cell renal cell carcinoma. The mitochondria in all three types of renal neoplasms studied differed in morphology, being predominantly uniform and round with prominent lamellar cristae packing the cytoplasm in renal oncocytoma. Ultrastructural examination of papillary RCC showed basal infoldings and increased mitochondria with glycogen granules.

\section{Discussion}

Classification of renal cell carcinoma is important from the treatment and prognosis point of view as well as for understanding of histogenesis. The main objective of this study was to establish the degree of inter-observer variation in sub-classification of renal cell carcinomas and to find out means of subtyping renal cell carcinoma short of cytogenetic studies. In the present study, cases were seen by four independent pathologists in a blinded manner and their diagnoses were compared. Out of these 278 renal tumors, concordant diagnosis was obtained in 250 cases whereas in the remaining 28 cases, diagnoses varied amongst the four pathologists. This data emphasizes the


Figure 3

Immunohistochemical staining using CK7 antibody showing strong and diffuse membranous positivity in chromophobe renal cell carcinoma(A) and collecting duct carcinoma(B) (CK7, ×200). 


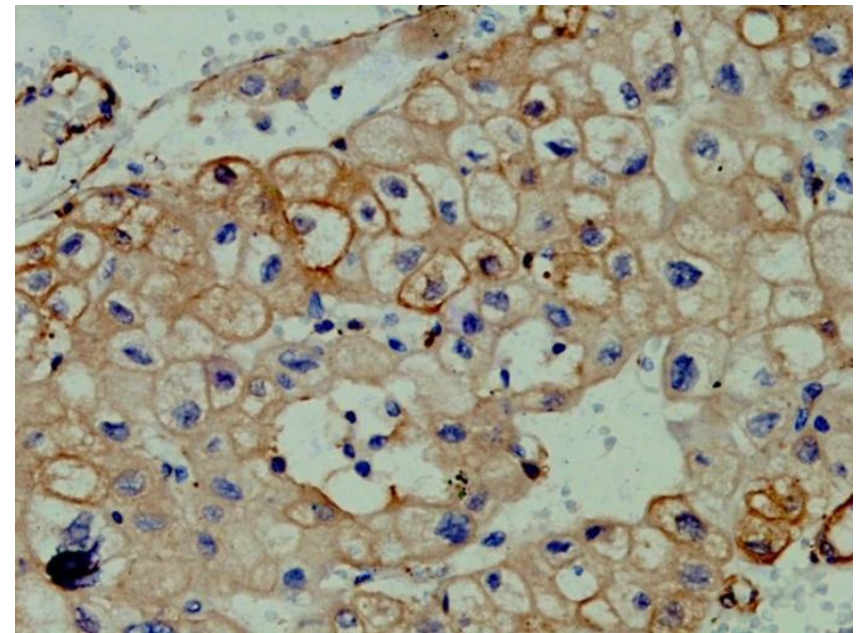

Figure 4

Photomicrograph showing weak but distinct vinculin positivity on the cell membrane of chromophobe RCC(Vinculin, $\times 200)$.

fact that haematoxylin and eosin histology alone is sufficient to classify a majority of renal cell carcinoma. However help from ancillary techniques may be required in approximately $10 \%$ of the cases.

Amongst the 278 cases, clear cell RCC was the commonest tumor with 208 (74.8\%) cases, followed by papillary RCC with $34(12.2 \%)$ cases, and chromophobe RCC with $22(7.9 \%)$ cases. There were only $5(1.8 \%)$ cases of renal oncocytoma, $1(0.4 \%)$ case of collecting duct RCC, and 8

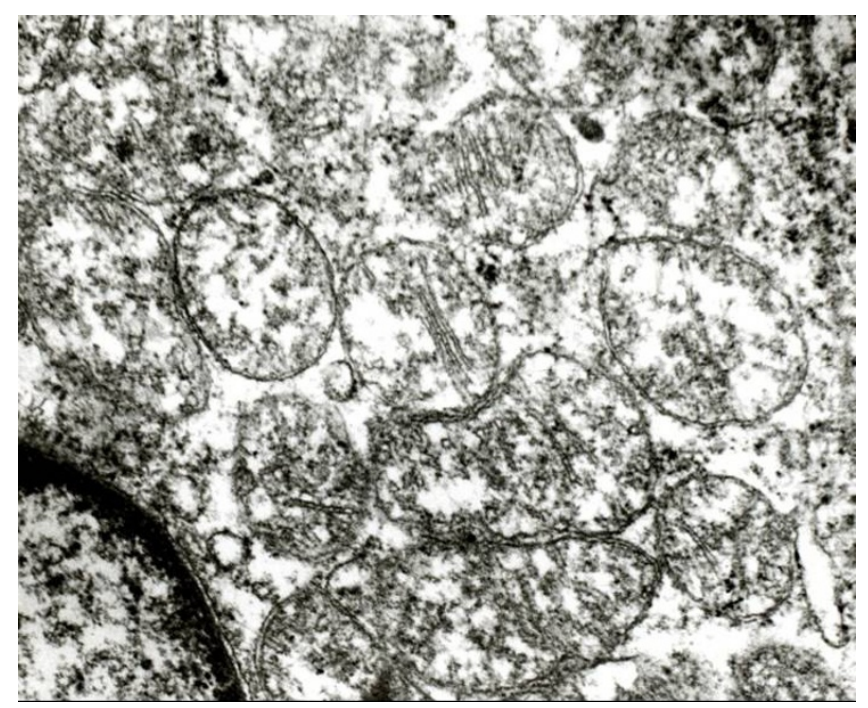

Figure 5

Electron microscopy showing numerous mitochondria packing the cytoplasm in oncocytoma (Uranyl acetate and lead citrate, $\times 10,000)$.
(2.9\%) cases of RCC, unclassified. This is comparable with the world literature, both western and Asian literature where clear cell RCC is the most common adult renal tumor with an incidence of as high as $75 \%$ of all RCC followed by papillary RCC which comprise $7-14 \%$ of RCCs (Table 3)[6,9-15]. Indian study by Srivastava et al[16] also showed clear cell RCC to be the most common adult renal tumor with $114 / 178(64.02 \%)$ cases (Table 3$)$.

The peak incidence of RCC in this study was in the fourth and fifth decades, in contrast to other studies in the western world, where the majority of cases were in their sixth and seventh decades [9-11]. The data in the present study also showed that the mean age of patients with chromophobe RCC and renal oncocytoma were less than the other sub-types. Literature from the western world show two to three fold male predominance in renal tumors. The data in the present study also showed similar results with a sex ratio, $\mathrm{M}: \mathrm{F}=2.3: 1$. However, the sex ratio was altered in chromophobe RCC and renal Oncocytoma where a marginal female predominance was seen. This data also varied with the world literature which shows male predominance in oncocytoma and equal sex incidence in chromophobe RCC [9-11].

Fuhrman grading of most (85\%) cases of clear cell renal cell carcinomas in our study was grade 1 and 2, and less than $5 \%$ was nuclear grade 4 . This data, however varied from the study by Srivastava et al[16] who showed $14.6 \%$ grade 1 tumor, $38.2 \%$ grade 2 tumor, $35.4 \%$ grade 3 tumor and $11.8 \%$ grade 4 tumor. Sarcomatoid change was seen in 5 cases of clear cell renal cell carcinoma, and in one case of papillary renal cell carcinoma. This is consistent with literature which shows less than $5 \%$ clear cell renal cell carcinoma with sarcomatoid dedifferentiation[10].

Vimentin was positive in $53.9 \%$ cases of clear cell renal cell carcinoma, $80 \%$ cases of papillary renal cell carcinoma, focally positive in one case of chromophobe RCC and diffusely positive in another case of chromophobe RCC with sarcomatoid areas. One case of collecting duct RCC showed focal positivity in stromal cells, however, oncocytomas $(0 / 5)$ showed negative vimentin staining. The result was comparable to the study by Dierick et al[17] who also found $53.3 \%$ positivity in cases of renal cell carcinoma. Similar findings have been reported by Waldherr et al[18] and by Holthofer et al[19]. However, vimentin immunostain did not prove to be useful in differential diagnosis of subtypes of renal cell carcinoma.

In this study, CK 7 was positive in $90 \%(9 / 10)$ cases of papillary renal cell carcinoma, $100 \%$ cases of chromophobe renal cell carcinoma, and the single case of collecting duct carcinoma. It was negative in all cases of clear cell 
Table 3: Comparison of incidence of Sub-types of Renal Cell Carcinomas with Western and Asian studies

\begin{tabular}{lllllll}
\hline & CCRCC & PRCC & CRCC & RO & CDC & UNCLASSIFIED \\
\hline Present Study(India) & $208(74.8 \%)$ & $34(12.2 \%)$ & $22(7.9 \%)$ & $5(1.8 \%)$ & $1(0.5 \%)$ & - \\
Srivastva et al [I7](India) & $114(64.0 \%)$ & $48(27.0 \%)$ & $14(7.86 \%)$ & - & $2(1.12 \%)$ & - \\
Zou et al [I2](China) & $77(67.5 \%)$ & $11(9.6 \%)$ & $14(12.3 \%)$ & - & - & $2(1.8 \%)$ \\
Patard et al[I3](France) & $3564(87.7 \%)$ & $396(9.7 \%)$ & $103(2.5 \%)$ & - & - & - \\
Kim et al[I4](Korea) & $686(86.3 \%)$ & $58(7.3 \%)$ & $49(6.16 \%)$ & - & $2(0.25 \%)$ & - \\
Gudbjartsson et al[I5](Iceland) & $558(88.7 \%)$ & $53(8.4 \%)$ & $13(2.1 \%)$ & - & - & - \\
Kovacs et al [6](Japan) & $80 \%$ & $10 \%$ & $5 \%$ & $5 \%$ & - & - \\
Amin et al[I6](USA) & $255(63 \%)$ & $75(18.5 \%)$ & $24(5.9 \%)$ & - & - & $23(5.7 \%)$ \\
\hline
\end{tabular}

renal cell carcinoma and renal oncocytoma. This result is comparable to the studies by Mathers et al[20] and Leroy et al[21] who showed positivity of CK7 in 100\% cases of chromophobe renal cell carcinoma, and one case of clear cell renal cell carcinoma. Study by Yang et al[22] showed $87-100 \%$ positivity of CK7 in papillary renal cell carcinoma. Hence, according to present study, CK7 is a helpful immunostain in differentiating ambiguous cases, particularly chromophobe versus clear cell RCC and papillary RCC versus conventional RCC with a papillary pattern.

Vinculin was weakly positive in only 2 out of 15 cases of chromophobe RCC, and single case of collecting duct RCC and was negative in all cases of clear cell renal cell carcinoma, papillary renal cell carcinoma and renal oncocytoma. Hence in this study, the vinculin immunostain was not of much use in resolving difficult cases. However, study by Kuroda et al[23] found vinculin positivity in $21.5 \%$ of all RCC.

The tinctorial characteristics of different renal epithelial neoplasms appear to be dependent on cytoplasmic contents, including various organelles[24]. Differential diagnoses between eosinophilic variant of clear cell renal cell carcinoma, oxyphil variant of chromophobe renal cell carcinoma and renal oncocytoma was resolved by electron microscopy. The mitochondria in these three types of renal neoplasms differed in morphology, being predominantly uniform and round with predominantly lamellar cristae in renal oncocytoma, variable in shape and size with predominantly tubulocystic cristae in chromophobe renal cell carcinoma, and swollen and pleomorphic with rarefied matrix and attenuated cristae in the eosinophilic variant of conventional (clear cell) renal cell carcinoma.

\section{Conclusion}

It can be concluded that incidence of different subtypes of renal tumours is similar to western and other Asian countries, however the age of presentation is one decade earlier than western population. In order to accurately subclassify renal cell carcinomas, the ancillary techniques required in a good surgical pathology set up consist of
Hale's colloidal iron stain, immunostain CK7 and electron microscopy. With the help of these three ancillary techniques it would be possible to resolve all difficult cases that one may be faced with.

\section{Competing interests}

The authors declare that they have no competing interests.

\section{Authors' contributions}

DP and KJ participated in selecting cases, carrying out immunohistochemistry, interpretation of results, and writing of the manuscript. NK and $\mathrm{AB}$ participated in the histopathological diagnosis, and editing of the manuscript. SKS provided the clinical details of the patients. All authors read and approved the final manuscript.

\section{References}

I. Jemal A, Murray T, Ward E, Samuels A, Tiwari RC, Ghafoor A, Feuer EJ, Thun MJ: Cancer statistics, 2005. CA Cancer J Clin 2005, 55:10-30.

2. Amin MB, Amin MB, Tamboli P, Javidan J, Stricker $H$, Venturina $M$, Deshpande A, Menon M: Prognostic impact of histologic subtyping of adult renal epithelial neoplasms: an experience of 405 cases. Am J Surg Pathol 2002, 26:28I-91.

3. Berg E Van den, Hout AH Van der, Oosterhuis JW, Storkel S, Dijkhuizen T, Dam A, Zweers HM, Mensink HJ, Buys CH, de Jong B: Cytogenetic analysis of epithelial renal-cell tumors: relationship with a new histopathological classification. Int J Cancer 1993, 55:223-7.

4. Thoenes W, Storkel S, Rumpelt H]: Histopathology and classification of renal cell tumors (adenomas, oncocytomas and carcinomas): the basic cytological and histopathological elements and their use for diagnostics. Pathol Res Pract 1986, I 81:125-43.

5. Murphy WM, Beckwith JB, Farrow GM: Tumors of the kidney, bladder, and related urinary structures. Armed Forces Institute of Pathology, Washington, DC; 1994.

6. Kovacs G, Akhtar M, Beckwith BJ, Burgert P, Cooper CS, Delahunt B, Eble JN, Fleming S, Ljungberg B, Medeiros LJ, et al:: The Heidelberg classification of renal cell tumours. J Pathol I997, I83:I3I-3.

7. Eble JN, Sauter G, Epstein JI, Sesterhenn IA, editors: World Health Organization Classification of Tumours. In Pathology and Genetics of Tumours of the Urinary System and Male Genital Organs Lyon: IARC Press; 2004.

8. Tickoo SK, Amin M, Zarbo RJ: Colloidal Iron Staining in Renal Epithelial Neoplasms, Including Chromophobe Renal Cell Carcinoma: Emphasis on Technique and Patterns of Staining. Am J Surg Pathol 1998, 22(4):419-24.

9. Moch H, Gasser T, Amin MB, Torhorst J, Sauter G, Mihatsch MJ: Prognostic utility of the recently recommended histologic classification and revised TNM staging system of renal cell carcinoma: a Swiss experience with $\mathbf{5 8 8}$ tumors. Cancer 2000, 89:604-|14. 
10. Young AN, Amin MB, Moreno CS, Lim SD, Cohen C, Petros JA, Marshall FF, Neish AS: Expression profiling of renal epithelial neoplasms: a method for tumor classification and discovery of diagnostic molecular markers. Am J Pathol 200I, I 58: I639-5I.

II. Cohen HT, McGovern FJ: Renal Cell Carcinoma. N Engl J Med 2005, 353(23):2477-90.

12. Zou H, Pang LJ, Hu WH, Li F, Li HA, Jiang JF, Liang WH, Sun ZZ Wang C, Lang JY: Study on clinicopathologic features and immunophenotype of $1 / 4$ cases of renal cell carcinoma. Zhonghua Bing Li Xue Za Zhi 2008, 37( I I):726-3I.

13. Patard Jj, Leray E, Rioux-Leclercq N, Cindolo L, Ficarra V, Zisman A, De La Taille A, Tostain J, Artibani W, Abbou CC, et al.: Prognostic value of histologic subtypes in renal cell carcinoma: a multicenter experience. J Clin Oncol 2005, 23( I 2):2763-7I.

14. Kim H, Cho NH, Kim DS, Kwon YM, Kim EK, Rha SH, Park YW, Shim JW, Lee SS, Lee SN, et al.: Genitourinary Pathology Study Group of the Korean Society of Pathologists. Renal cell carcinoma in South Korea: a multicenter study. Hum Pathol 2004, 35(I2):1556-63.

15. Gudbjartsson T, Hardarson S, Petursdottir V, Thoroddsen A, Magnusson J, Einarsson GV: Histological subtyping and nuclear grading of renal cell carcinoma and their implications for survival: a retrospective nation-wide study of 629 patients. Eur Urol 2005, 48(4):593-600.

16. Srivastava A, Mandhani A, Kapoor R, Jain M, Dubey D, Srivastava A, Raghavendra M, Kumar A: Prognostic factors in patients with renal cell carcinoma: Is TNM (1997) staging relevant in Indian subpopulation? Indian J Cancer 2004, 4 I(3):99-I03.

17. Dierick AM, Praet M, Roels H, Verbeeck P, Robins C, Oosterlinck W: Vimentin expression of renal cell carcinoma in relation to DNA content and histological grading: a combined light microscopic, immunocytochemical and cytophotometrical analysis. Histopathology 1991, 18:315-22.

18. Waldherr R, Schwechheimer K: Co-expression of cytokeratin and vimentin intermediate-sized filaments in renal cell carcinomas. Virchows Arch A Pathol Anat Histopathol. 1985, 408(I): $15-27$

19. Holthofer H, Miettinen A, Paasivuo R: Cellular origin and differentiation of renal cell carcinomas. Lab Invest 1983, 49:317-26.

20. Mathers ME, Pollock AM, Marsh C, O'Donnell M: Cytokeratin 7: a useful adjunct in the diagnosis of chromophobe renal cell carcinoma. Histopathology 2002, 40:563-7.

21. Leroy X, Moukassa D, Copin MC, Saint F, Mazeman E, Gosselin B: Utility of cytokeratin 7 for distinguishing chromophobe renal cell carcinoma from oncocytoma. Eur Urol 2000, 37:484-487.

22. Yang XJ, Tan MH, Kim HL, Ditlev JA, Betten MW, Png CE, Kort EJ, Futami K, Furge KA, Takahashi M, et al.: A Molecular Classification of Papillary Renal Cell Carcinoma. Cancer Res 2005, 65(13):5628-37.

23. Kuroda N, Naruse K, Miyazaki E, Hayashi Y, Yoshikawa C, Ashida S, Moriki T, Yamasaki Y, Numoto S, Yamamoto Y, et al.: Vinculin: Its Possible Use as a Marker of Normal Collecting Ducts and Renal Neoplasms with Collecting Duct System Phenotype. Mod Pathol 2000, I3(I0): I I09-14.

24. Krishnan B, Truong LD: Renal epithelial neoplasms: The diagnostic implications of electron microscopic study in $\mathbf{5 5}$ cases. Hum Pathol 2002, 33:68-79. http.//www.diagnosticpathology.org/content/4/1/21 